\title{
Peter Graham with Ian McKay, Radical Ambition: The New Left in Toronto (Toronto: Between the Lines Press, 2019). 515 pp. Paperback \$35.95.
}

Peter Graham's Radical Ambition is a complex, thematically organized monograph on the history of Toronto's new left between 1958 and 1985. Based on a dissertation, the book was written in collaboration with Ian McKay, Graham's dissertation supervisor, in light of the latter's path-breaking Gramscian framework for researching historical Canadian left "formations." While Toronto's new left can be understood as those who were affiliated with or laid claims to the label, namely "academics, peace activists, radical students, feminists, gay liberationists, anti-racist activists, builders of vanguard parties, and cultural workers" (16), Graham makes an overriding case for understanding it in consistently complex, occasionally contradictory, and often "diffuse" terms, its significance "difficult to pin down" (19, 411).

Radical Ambition begins in the mid-1950s with the Toronto left's efforts to defend free speech against McCarthyism (26-28). It then characterizes its efforts until 1965 as establishing "an emergent paradigm" of new left politics (57). Only between 1965 and 1967 is a retrospectively recognizable "new left" formation discernible, its bold "direct action" provoking some, like then professor Kenneth McNaught, to warn, in ominous terms, of the perceived danger its "grand, amorphous assault upon "the establishment" posed to "liberal-constitutional values" (107). The Toronto new left's seemingly "amorphous" character soon eclipsed its apparent "grand" pretensions, however, its defining components, evident by 1968, becoming a loose, often imported, typically individually negotiated conglomeration of national liberationist, personal autonomist, cultural revolutionary, politically pre-figurative, and community-oriented ideologies or orientations (49). As Graham goes on to note, several of these elements would prove subsumable by a new and parallel "radical liberalism," such as that espoused in 1969 by Toronto Liberal mayoral candidate Stephen Clarkson (181-182).

As in other parts of the world, Toronto's radical new leftists would seek to correct and discipline the new left's "amorphous" tendencies by reviving or transplanting and then aggressively promoting membership in revolutionary party-style Leninist, Trotskyist, or Maoist organizations, operated independently of the Communist Party of Canada and the New Democratic Party (184). The Canadian Party of Labour, an acute iteration of the same, sought to replace what it regarded as the new left's 'backward 'ethnic' cultural forms ... with a new culture of everyday struggle and worker internationalism" (194). What little success such groups enjoyed was typically achieved, Graham suggests, by exerting quasi-authoritarian control over 
their members. A notable exception to this tendency was the Canadian Worker's Project Century: 2 (CWPC2), founded in 1970, which sought to realize a Rosa Luxemburg-inspired "creative Marxism" (196). By the early 1980s most of these ultramilitant organizations were either in crisis or verging on collapse (374-376). Instead of a working-class orientation, in broad terms Toronto's new left consistently focused throughout the 1970s on "anti-racism" (294), followed at a distance by a parallel but often submerged "drawing" and "redrawing" of boundaries between emergent social and radical feminist orientations (303), both making greater consistent use of "consciousness raising" techniques $(168,297)$ than most other Toronto new left iterations.

In contrast, most Toronto new leftists would be content to bypass vanguard-based militancy in favour of pragmatic community-building and "participatory democracy" projects $(120,218)$. The nature and dynamics of these different projects varied. Some sought to build democratic communities in and through existing institutions, as when education activists, who had initially pioneered "alternative schools," changed course and began building democratic, locally-controlled public schools, termed "community schools" (119). At the same time, others sought to organize Toronto's tenants, who constituted fifty per cent of the city's residents by 1974 (219), into "collective bargaining" units capable of staging rent strikes (223), while still others pioneered and struggled to protect from demolition or gentrification market housing-based co-ops or communes, the twenty to thirty affiliated "counterculture" houses located in Toronto's then Beverley Street "Red Belt" district being the most notable and successful example (221).

By the early 1980s though, Graham attests, new left gains in Toronto would be greatest and longest lasting "in spheres relatively autonomous from the market" (284), attempts at colonizing the market, its cable television networks for instance, achieving "limited success" (281). Thereafter, he adds, radical Toronto appears to take a partly radical feminist inspired anarchist turn, no fewer than twentyfive such initiatives being said to emerge in the city in the early 1980 s $(407,409)$. Ultimately, he concludes:

The new left's sheer heterogeneity and diffuseness, the scales from the very local to the universal upon which the cultural revolutionaries worked, although in some respects a sign of their strength, also made it difficult for them to share a unifying narrative with activists working in different spheres and on different scales (285).

Without explicitly saying so though, he strongly suggests this outcome resulted, first and foremost, from the Toronto new left's failure to establish and share in common a comprehensive analysis of "capitalist society" (193).

Radical Ambition is not merely a book about an ambitious historical left 
formation; it is also, in its own right, a radically ambitious book. Does it do all it should? If it can be said that its thematic organization interferes with its reader's chronological comprehension of the same material, a strict chronological approach would likely result in a cognitively undigested ream of facts. If it can be said that its delimited focus on Toronto's new left assumes a good deal of prior historical knowledge of its reader, a full contextualization would likely result in a tome twice its already appreciable length, though a more parallel but sustained focus on the crossfertilization resulting from the constant flow of Toronto new leftists in and out of the provincial and federal NDP (415) would be one justifiable extension of the book's scope. As well, it is often not clear whether the broad theoretical frameworks invoked in the book's first chapter, "capitalist modernity" (5-6, 11, 15), and a sixscale model of Toronto and its new left formation (18), actively shape or inform its structure and content.

These factors aside, Radical Ambition, particularly in its capacity as a methodologically and empirically rather than theoretically driven study, undoubtedly possesses more strengths than weaknesses. Students of history will appreciate the exemplary manner in which its comprehensive framework brings together distinct yet interrelated subjects that would be exceedingly challenging to research individually. Activist readers, meanwhile, will find the stories it tells uncannily resonant with the social and political dynamics of the present, though what sorts of conclusions this fact warrants remains an open question. Lessons abound as to the origins and track record of strategies or tactics still foisted on rank and file activists today, while other stories Graham reconstructs confirm ways Canadian left formations make measurable hegemonic gains in even seemingly adverse circumstances. At the same time, Graham's book clearly highlights two contradictions internal to both Toronto's new left and today's progressive social movements: demanding rights of the same political order one otherwise vows to transform or overthrow (313), as well as the dependency of some social movements on state grants or funding (125), particularly when this dynamic transforms the resulting entity into a "quasi-state" agency (329).

John A. McCurdy York University 